Fecha de recepción: marzo 2020

Fecha de aceptación: abril 2020

Versión final: junio 2020

\section{Mujer y Cine ¿hay lugar para la heroína?}

Andrea Pontoriero ${ }^{(1)}$

Resumen: Cuando Campbell habla del camino del héroe, lo hace en masculino. Está naturalizado que ese topos esté ocupado por un héroe y no una heroína. El "trayecto" cumple con una estructura, una serie de "momentos" que se repiten en el camino de todo héroe. Esa estructura la vemos repetirse una y otra vez en la mayoría de las historias que se nos narran desde los comienzos de la humanidad a la actualidad. Lo interesante del planteo de Campbell es que esa estructura se repite a nivel del inconsciente cuando hacemos el pasaje entre la niñez y nuestra vida adulta. Es por esto que todas esas historias, mitos, que son repetidos de generación en generación calan tan profundo en todos los humanos que comparten una misma cultura. Todos atravesamos con esfuerzo y muchas veces con dolor esa etapa en la que buscamos nuestra identidad, en que nos transformamos en un adulto que va a ocupar un lugar en la sociedad.

En este trabajo vamos indagar sobre el trabajo de una cineasta argentina del siglo XX, María Luisa Bemberg, quien a través de su obra y de su práctica como guionista y directora cinematográfica puso en cuestión algunos valores culturales naturalizados respecto a qué es ser mujer. Lo hizo en la temática de sus films pero también en su práctica profesional. Se la conoce como la primera directora cinematográfica argentina. Logró ser reconocida por su trabajo en un entorno con un alto porcentaje de trabajadores varones y en la mayoría de sus proyectos se apoyó en la producción de otra mujer: Lita Stantic, lugar que tampoco era común que fuera ocupado por una mujer. Para esto vamos a trabajar algunos de los estereotipos femeninos que se discuten en su filmografía, historizando la construcción de los mismos.

Palabras clave: Cine - Mujer Bemberg - feminismo - héroe - heroína - mito - nomos hegemonía - estereotipos.

[Resúmenes en inglés y portugués en las páginas 82-83]

(1) Andrea Pontoriero. Maestría en Gestión del Diseño (UP, 2017). Licenciada en Artes (UBA, 1998). Profesora de Enseñanza Media y Superior en Artes (UBA, 1998). Profesora y Coordinadora del Área de Teatro Espectáculo y Música de la Facultad de Diseño y Comunicación de la Universidad de Palermo desde 2014. Es actriz y directora teatral. Entre sus creaciones se destaca Prueba de Amor de Roberto Arlt. Obtuvo premio como "Actriz Revelación" por su actuación en La gaviota de Chejov. Ha presentado sus trabajos académicos en numerosos Congresos y Jornadas Nacionales e Internacionales. 
Cuando Campbell habla del camino del héroe, lo hace en masculino. Está naturalizado que ese topos esté ocupado por un héroe y no una heroína. El "trayecto" cumple con una estructura, una serie de "momentos" que se repiten en el camino de todo héroe. Esa estructura la vemos repetirse una y otra vez en la mayoría de las historias que se nos narran desde los comienzos de la humanidad a la actualidad. Lo interesante del planteo de Campbell es que esa estructura se repite a nivel del inconsciente cuando hacemos el pasaje entre la niñez y nuestra vida adulta. Es por esto que todas esas historias, mitos, que son repetidos de generación en generación calan tan profundo en todos los humanos que comparten una misma cultura. Todos atravesamos con esfuerzo y muchas veces con dolor esa etapa en la que buscamos nuestra identidad, en que nos transformamos en un adulto que va a ocupar un lugar en la sociedad.

Veamos, para comenzar, de qué estamos hablando cuando decimos "trayecto del héroe". Campbell desarrolla este concepto, principalmente en su obra El Héroe de las mil caras. Precisamente habla de "el" héroe porque hay solamente un trayecto, una sola estructura que se repite en todas las historias. El héroe, es uno que adopta diferentes caras, diferentes máscaras. Puede ser físico como Heracles o espiritual como Cristo o Mahoma. Pero el camino es el mismo, para Neo en Matrix o para Po en Kunfu Panda, por nombrar dos ejemplos dispares. El trayecto del héroe plantea un pasaje, una iniciación, una separación del lugar de confort y un adentrarse en la aventura de lo desconocido, ya sea esto último un estadío superior de la conciencia, el mundo dominado por las máquinas de Matrix o nuestra humilde decisión de irnos a un país lejano a estudiar una carrera. Todas estas variantes de las más espirituales a las más cotidianas implican una separación y una iniciación.

La primera fase de esta estructura consiste en una "llamada" a la aventura. Según Campbell (1959):

Este primer estadio de la jornada mitológica, que hemos designado con el nombre de "la llamada de la aventura", significa que el destino ha llamado al héroe y ha transferido su centro de gravedad espiritual del seno de su sociedad a una zona desconocida. Esta fatal región de tesoro y peligro puede ser representada en varias formas: como una tierra distante, un bosque, un reino subterráneo, o bajo las aguas, en el cielo, una isla secreta, la áspera cresta de una montaña; o un profundo estado de sueño; pero siempre es un lugar de fluidos extraños y seres polimorfos, tormentos inimaginables, hechos sobrehumanos y deleites imposibles. (Campbell, p.40)

El héroe puede decidir adentrarse en la aventura es decir responder esa llamada o negarla, en este segundo caso su vida continuará como antes pero llena de infelicidad, una víctima de la rutina y de la cultura, que debe ser salvada. Lo que nos interesa es cuando el héroe decide recorrer su camino y por lo tanto cruza el "portal". Campbell hace la salvedad de que el héroe sólo puede contestar la llamada cuando está listo para hacerlo. Es entonces que emprende la aventura donde va a tener que pasar pruebas de todo tipo para poder transformarse, iniciarse.

Dentro de esa iniciación, Campbell marca sub etapas, que son: el encuentro con la diosa, la mujer como tentación y el reencuentro con el padre. Aquí nos detenemos porque como 
se ve, el héroe es en masculino y lo femenino y lo masculino parecen implicar desafíos diferentes en la iniciación, en el encuentro de la propia identidad. Entonces cuando hablamos de trayecto de la heroína, vamos a tener la necesidad de repensar estas estructuras. ¿Es esto posible?

Una vez que el héroe hace su trayecto, accede a una de las pruebas más elevadas el "encuentro con la diosa":

La mujer, en el lenguaje gráfico de la mitología, representa la totalidad de lo que puede conocerse. El héroe es el que llega a conocerlo. Mientras progresa en la lenta iniciación que es la vida, la forma de la diosa adopta para él una serie de transformaciones; nunca puede ser mayor que él mismo, pero siempre puede prometer más de lo que él es capaz de comprender. Ella lo atrae, lo guía, lo incita a romper sus trabas. Y si él puede emparejar su significado, los dos, el conocedor y el conocido, serán libertados de toda limitación. La mujer es la guía a la cima sublime de la aventura sensorial. (Campbell (1959), p. 71)

Es volver al útero, al ombligo del mundo donde las energías fluyen. Es el encuentro con lo inconsciente. Es el vientre de la ballena, adentrarse en lo desconocido, el paso al reino de la noche.

Es un descenso a la oscuridad. Psicológicamente la ballena representa el poder de la vida apresado en el inconsciente. Metafóricamente, el agua es el inconsciente, y la criatura en el agua es la vida o la energía inconsciente que ha abrumado a la personalidad consciente y debe ser vencida y dominada (Campbell (1991), p. 207)

Luego de este pasaje el héroe debe reconciliarse con el padre, pero antes de esto la mujer puede actuar como tentación, es el caso de las sirenas que con su canto no le permiten al héroe continuar con su misión. Pero el encuentro con la identidad implica reconciliarse con el padre. La única certeza en un mundo sin prueba de ADN es la salida del útero materno, no se puede estar seguro de la paternidad, por consiguiente toda la construcción patriarcal asociada a los mitos, a las historias de la búsqueda de la identidad tienen que ver con la búsqueda del padre.

Esta estructura tiene que ver con los estereotipos que se crean social y culturalmente y de los cuales nos apropiamos para poder ser parte de una determinada sociedad. Para trabajar los conceptos de cultura y sociedad y el rol que juegan los mitos tomaremos a Berger (1969) Este autor, para definir la cultura parte de la idea de que el hombre (nuevamente se utiliza este término como genérico) está incompleto biológicamente, no existe para él un mundo humano que lo contenga como sí existe un mundo animal donde estos pueden sobrevivir por instinto. Al no existir ese mundo humano, el hombre debe crearlo y ese mundo es la cultura. La cultura es entonces, para Berger lo que nos hace humanos, lo que nos diferencia de los animales. Tiene una visión amplia de la misma considerando que todos los productos humanos son cultura pero cada cultura depende de la sociedad que la construye porque la creación cultural se hace colectivamente. Esa construcción se 
da por un procedimiento dialéctico de tres momentos en los cuales la cultura se crea por "externalización", es decir desde los propios humanos se construye ese mundo humano, la cultura, como un andamiaje que los sostenga, luego se "objetiviza", es decir, la cultura toma entidad propia, es un objeto que está fuera de los humanos y finalmente el tercer movimiento es la "internalización" que es el momento en el cual todo ese conjunto de valores culturales, deben ser incorporados por los humanos para poder ser parte de esa cultura y esa sociedad. En realidad en nuestras vidas cronológicas el proceso se da al revés: cuando somos bebés, durante nuestra infancia y adolescencia empleamos la mayor parte de nuestro tiempo internalizando los valores culturales, el lenguaje, y eso, es lo que nos hace ser parte de la sociedad. Lo que adquirimos a través de los distintos procesos educativos es lo que Berger llama un nomos, el orden significativo común, el conjunto de valores, creencias que nuestra sociedad define como propias y que la diferencia de las otras. Este nomos, este orden significativo común, se va construyendo socialmente y se hegemoniza, es decir, es el que aceptamos como válido, es ese andamiaje que se propone a sí mismo como estable y que nos contiene y nos da seguridad, por eso los valores culturales cambian muy lentamente. Las ideas de familia, de matrimonio, de lo femenino y lo masculino, parecen ser valores que siempre estuvieron ahí y no se discuten, están naturalizados. Su cambio es mucho más lento cuando las sociedades legitiman esos nomos a través de la religión porque en ese caso ese orden significativo común se establece como sagrado y resulta mucho más difícil cambiarlo. Pero aún en las sociedades modernas en donde el poder político está separado de lo religioso, hay muchas prácticas que llevan mucho tiempo cambiarlas porque en cierta forma el ir contra el nomos es colocarse en la anomia y quedarse fuera de la sociedad. Estos cambios incluso a veces parecen imposibles porque los valores y las creencias están tan "naturalizados" que ir contra ellos es perder la identidad propia, ser un paria.

Los mitos, las historias que narran los comienzos de nosotros mismos son los que nos explican, los que nos dan entidad, Campbel enfatiza:

"el mito es la entrada secreta por la cual las inagotables energías del cosmos se vierten en las manifestaciones humanas" (Campbell (1991), p.11)

y agrega que

"La finalidad de los rituales es conducir a los pueblos a través de los difíciles umbrales de las transformaciones que demandan un cambio de las normas no sólo de la vida consciente sino de la inconsciente (Campbell (1991), p.16)

Veamos la relación de esta idea con la definición de mito que plantea Mircea Eliade (1992), Este autor, define al mito como una historia que narra cómo a través de la intervención de seres sobrenaturales algo ha venido a ser, a existir, pero aclara que el mito no es tal sin un ritual que lo re-cree, eso es lo que lo mantiene vivo. Nosotros, con nuestro comportamiento ritual renovamos los lazos que nos mantienen unidos como sociedad. Contar, narrar nuestras historias, nuestros mitos, hacen que renovemos nuestras creencias, que mantengamos vigente el "nomos" del que habla Berger, que lo naturalicemos. Es 
por esto que nos parece relevante destacar, con el fin de "desnaturalizar" estos valores anquilosados, el rol que juega el arte y todos los lenguajes creativos a la hora de crear nuevos mundos posibles en donde se discutan valores. Porque en un mundo moderno en donde lo religioso se separó de la vida cotidiana, es en las historias, en el cine, en el teatro, en la literatura, en los videojuegos, en donde internalizamos el orden significativo común pero también en donde a partir de nuestras prácticas, nuestra creatividad, podemos discutirlo, re-pensarlo, re-crearlo.

En este trabajo vamos indagar sobre el trabajo de una cineasta argentina del siglo XX, María Luisa Bemberg, quien a través de su obra y de su práctica como guionista y directora cinematográfica puso en cuestión algunos valores culturales naturalizados respecto a qué es ser mujer. Lo hizo en la temática de sus films pero también en su práctica profesional. Se la conoce como la primera directora cinematográfica argentina. Logró ser reconocida por su trabajo en un entorno con un alto porcentaje de trabajadores varones y en la mayoría de sus proyectos se apoyó en la producción de otra mujer: Lita Stantic, lugar que tampoco era común que fuera ocupado por una mujer. Para esto vamos a trabajar algunos de los estereotipos femeninos que se discuten en su filmografía, historizando la construcción de los mismos.

La cinematografía de María Luisa Bemberg es ubicada por muchas teóricas dentro del feminismo. No es del interés de este trabajo discutir esta noción pero sí tomar su obra como un exponente temprano, en nuestro país, de discusión y desnaturalización de los estereotipos femeninos. Al respecto Trebisacce (2013) y Giunta (2014) realizan un recorrido por la obra de María Luisa Bemberg contextualizándola en el feminismo argentino de los años 70.

Entre 1970 y 1975 se formaron distintas organizaciones feministas en la Argentina que se inscribieron en las demandas de la segunda ola del feminismo: en 1970 la Unión Feminista Argentina (UFA) fundada por Nelly Bugallo, Leonor Calvera, María Luisa Bemberg y Gabriella Roncorini de Christeller, agrupación que abrió el camino para la formación de otros grupos como Muchacha o el grupo Nueva Mujer (Giunta, p. 6)

Dentro de este contexto es que María Luisa Bemberg realiza sus primeros trabajos como directora: los cortos El mundo de la mujer en 1972 y Juguetes en 1978. En el primero, Bemberg ironiza sobre los imperativos femeninos: coloca su cámara en la Feria Rural de Palermo de 1972 donde se exponían "productos femeninos" como la ropa, los peinados, el cuidado del cuerpo. El efecto burlón se produce porque las imágenes que se muestran tienen que ver con exponer a las mujeres a horas de peinados sofisticados, máquinas para adelgazar, maquillaje, todos productos destinados a alimentar el estereotipo de belleza femenina y al mismo tiempo una voz en off lee consejos de cómo ser una buena esposa y una buena ama de casa, lo cual implica pasar la aspiradora, cocinar y ser bella, limpia y ordenada. El otro efecto burlesco se produce porque se escucha la banda de sonido del cuento de Walt Disney Cenicienta lográndose un efecto crítico y distanciador con los estereotipos femeninos que se muestran en las imágenes. En el segundo corto Juguetes (1978), Bemberg llama la atención de cómo se construye la idea de los masculino y lo fe- 
menino a partir de estereotipar actividades con los juegos infantiles. Estos dos problemas que se plantean en sus cortos a partir de un material documental atravesado, distanciado e ironizado por el tratamiento de edición y montaje al que los somete también se van a discutir en sus largos de ficción.

En Señora de nadie (1982) Bemberg toma al personaje de Luisina Brando quien es una señora burguesa que vive con su marido y sus hijos hasta que se da cuenta que su marido le es infiel y decide dejarlo a él y a sus hijos. Parece una resignificación de Nora en Casa de Muñecas de Ibsen. Pero Bemberg focaliza en la vida de su personaje una vez que cambia de vida, su conflicto no pasa por dejar atrás el mandato social de la esposa y madre perfecta, deja el rol que le asigna la sociedad con total naturalidad y la película focaliza en su búsqueda como mujer que no es de nadie. Aquí, el acento está puesto en que la "llamada a la aventura" es el reconocimiento de la infidelidad de su esposo, eso hace que deje su vida de comodidad y se interne en lo desconocido: ganarse la vida trabajando, buscar solidaridad en familiares y amigos.

La autora Kratje (2017) hace un análisis exhaustivo del film Camila (1984) que es el más reconocido de esta directora. Lo utiliza para abordar la historización del cine y el feminismo en la Argentina. Básicamente, la historia de Camila trata de una mujer/niña que se enamora de un sacerdote y huyen juntos a vivir su amor. Lo que nos interesa resaltar de su lectura para poder ligarlo con el camino de la heroína es la transformación del personaje de Camila como sujeto de deseo. Para hacer este análisis la autora compara la narración de la historia de Camila en el film de Bemberg con las narraciones existentes sobre Camila O'Gorman, el personaje histórico. Llama la atención nuevamente en este caso la relación con el Naturalismo del siglo XIX. Una de las marcas del mismo es la relación que se hace en sus textos al tema de la "herencia": si un personaje es corrupto o tiene una determinada enfermedad de la "conducta" es muy probable que se la pase a su descendencia. En las historias que se cuentan de Camila O'Gorman se la asocia con su abuela: la Perichona. Esta mujer se la conoció por ser la amante de Liniers y tener una conducta "relajada" en cuanto a su "honor". Por otra parte en la documentación que existe sobre la historia de Camila se hace hincapié en que la culpa de la huída con el sacerdote recae en el sacerdote, no en ella. Es la historia del rapto, que aparece en los mitos más antiguos y en el siglo XIX en el Romanticismo rioplantense se re-crea a través del mito de la cautiva.

En los documentos que testimonian los sucesos históricos, Camila es presentada como víctima de Uladislao: "Quien primero denunció la fuga ante Juan Manuel de Rosas fue el padre de Camila. En una carta del 21 de diciembre, Adolfo O'Gorman le da cuenta del acto más atroz y nunca oído en el país. Pero no se limita a informarle, sino que le pide severo castigo para ambos y la captura de su hija para evitar que la infeliz, creyéndose perdida, se precipite en la infamia. (Kratje, p. 34)

El temor del padre de Camila es que se pierda como su abuela la Perichona, Camila es vista como un objeto, como un cuerpo raptado por el deseo del hombre, pero en el film, Bemberg da vuelta esta idea y hace foco en el deseo de Camila. Para hablar sobre esto, Kratje toma a Laura Mulvey (1975) quien indaga cómo el cine narrativo a través de la 
puesta de cámara y la identificación que se produce con la mirada del espectador hace que las mujeres aparezcan como objeto de deseo. En su argumentación Kratje (2014) muestra cómo Bemberg da vuelta esta concepción.

La apropiación de la mirada por parte de Camila transforma a Ladislao en un objeto de deseo. Ello propicia una transgresión de las clásicas convenciones cinematográficas: Camila, en tanto sujeto deseante, se disloca del lugar convencional de objeto erótico que connota "mirabilidad" (to-looked-at-ness, según la conocida expresión de Mulvey), poniéndose en cambio en la posición de portadora de una mirada propia, como la instancia más activa de la relación sexual. (Kratje, p. 36)

Como en todas las películas de María Luisa Bemberg los personajes femeninos son sujetos que rompen con los estereotipos y los mandatos sociales, en el caso de Camila estos están encarnados en el Estado y en la familia. En su próximo largo Miss Mary (1986) también trabaja sobre el deseo, la hipocresía de la clase alta y los mandatos familiares. Una vez más aparece el matrimonio como una especie de "cárcel" para las mujeres del cual no pueden escapar si quieren seguir perteneciendo a su casta. La protagonista de la historia, Miss Mary, no entra dentro de este patrón, y su precio es vivir en una tierra lejana del Imperio, enseñando buenos modales e inglés a niños de la clase acomodada bonaerense, en un mundo que no es el suyo y que para colmo se ve amenazado por el "peronismo".

En Yo, la peor de todas (1990) es dondeBemberg aborda más profundamente los estereotipos femeninos respecto de lo intelectual. La protagonista de esta historia es Sor Juana Inés de la Cruz, una mujer que en el siglo XVII para poder desarrollar sus inquietudes intelectuales y su falta de interés en el matrimonio, tuvo que ordenarse monja. La autora Rivera Garretas al analizar el parentesco y la espiritualidad femenina en Europa trabaja cómo la elección de algunas mujeres de dedicarse a la vida espiritual dentro de la iglesia en la Edad Media es una forma de resistencia al modelo patriarcal que dispone de los cuerpos femeninos a través del matrimonio. Toma como ejemplo a la monja Hrotsvitha de Gandersheim quien en el siglo X escribía teatro y cuyos textos abundaban en la ironía para poder expresar sus ideas. Una de las cuestiones que plantea Rivera Garretas y que claramente aparece en la película de Bemberg es que a las mujeres se les tiene vedado hablar en público. El discurso de Sor Juana se encuentra relegado a la privacidad, su cuerpo encerrado en una celda y sólo se le permite hablar atrás de las rejas. El problema no es su palabra, sino que esta se haga pública.

En el Occidente greco-romano-cristiano, se entiende que un cuerpo femenino está desnudo, no cuando no lleva un velo que le cubra la cabeza y el rostro, sino cuando habla. Especialmente, cuando habla en público; en el caso del cristianismo, especialmente cuando habla en la iglesia, lugar común de los cristianos en el cual la palabra femenina es percibida como "indecorosa". Ha explicado así esta tradición (en lo que al mundo clásico se refiere) Ana Iriarte: "A lo largo de este recorrido en busca del lugar reservado a la palabra femenina en la civilización que definió el silencio como «el mejor adorno de la mujer», se ha ido 
descubriendo que la línea fronteriza trazada por los griegos entre el universo femenino y el masculino incluye la atribución a la Mujer de un lenguaje enigmático que aparece íntimamente relacionado con el comportamiento discreto que ésta debe aportar. No sólo la desnudez compromete la actitud púdica inherente al Ideal de feminidad, sino también el hecho de hacerse oír: en público, la palabra de las mujeres, al igual que sus cuerpos, debe aparecer encubierta. (Rivera Garretas, p. 38)

Sor Juana es obligada a abjurar de su palabra, de su conocimiento, le es permitido que circule mientras tiene y mantiene relaciones con el poder pero cuando la protección se cae, debe declararse La peor de todas. Hasta ahora los estereotipos femeninos con los que rompe el cine de Bemberg tienen que ver con el matrimonio y el deseo femenino en cuanto a lo erótico. Y aquí son interesantes los análisis que hacen Giunta y Trebisacce enmarcándola dentro del movimiento feminista y las luchas a partir de los 70 . En los 80, cuando filma Bemberg la mujer en el poder aún no es concebible, no habíamos tenido experiencias de presidentas en femenino, las leyes de cupo para las mujeres en las cámaras de diputados y senadores aún no se habían transformado en una realidad y el rol de las mujeres en el campo artístico como líderes de proyectos también era algo que recién empezaba a concebirse salvo en raras excepciones. En este film aparece como punta de lanza esta problemática. El trayecto de la heroína aquí es intelectual, es adentrarse en un mundo que está visto como masculino y que las mujeres tienen vedado, la palabra pública. Pasemos al último de sus films De esto no se habla (1992). Aquí aparece otra figura interesante que va a ser una de las luchas más activas de la actualidad y que en este film aparece esbozado pero, según nuestro punto de vista el giro que se le da a esta problemática lo devuelve a una postura conservadora. La trama se desarrolla en un pueblo y el sujeto de la acción es una mujer, el personaje de Luisina Brando que es una madre, sola, no soltera, sola, que no permite que se diga que su hija es enana, o si se quiere ser más políticamente correcta, tiene enanismo. Eso es de lo que no se habla. Aquí aparece una disidencia, un cuerpo que no aparece dentro del canon hegemónico de lo que es ser un cuerpo, es un diferente pero si bien la película trata sobre este personaje, no se lo establece como sujeto hasta el final de la película. La hija enana está en función de la madre que arma toda su vida como una escena que ella controla. Es interesante como esta madre negadora tiene tan naturalizado qué es lo normal que cuando el personaje de Marcello Mastroiani, obviamente el hombre más codiciado del pueblo le quiere hablar en privado sobre un asunto importante, ella piensa que le va a declarar su amor a ella, no sospecha ni por un momento que el objeto del amor de este hombre puede llegar a ser su hija enana. El matrimonio se produce entre la enana y el hombre más deseado del pueblo. Esto, ya configura una alteración del orden de lo que se supone "natural" y "normal" y todo acontece y es aceptado en el pueblo. Se los muestra felices, y como espectadores se nos incomoda haciéndonos cuestionar a nosotros mismos nuestras formas de entender lo deseable, lo normal poniendo en crisis nuestros sistemas de valores. Los estereotipos con los cuales juzgamos y valoramos a los otros. Pero, llega al pueblo un circo. Hasta ahora, la madre utilizando su poder no había permitido que se acercasen circos al pueblo, pero esta vez no lo pudo impedir y su hija enana, felizmente casada, entra en contacto con los enanos 
del circo y decide irse con ellos, aquí es donde este personaje se transforma en Sujeto. $\mathrm{Y}$ entonces nos preguntamos ¿los enanos sólo pueden ser felices con enanos? ¿El lugar de los enanos es el circo? ¿Por qué? Y además en la película estamos hablando de una enana. Es como si, también en este film cuando el personaje toma las riendas de su vida, nuevamente para buscar su identidad tiene que salirse de la "normalidad" de la institución matrimonial. El umbral que cruza esta heroína es salir de su pueblo, del cuidado de su madre y de su esposo para largarse a la aventura del circo. Pero, habría que ver si en esta aventura, el circo no funciona como otra atadura que tiene que ver con estereotipar al diferente y sólo dejarlo "circular" por los lugares en los que se supone que tienen que estar "naturalmente".

Las historias, las películas, a través de la creación de sus universos ficcionales, nos resignifican nuestra forma de entender nuestro estar en el mundo. Las creaciones, esos objetos que están ahí y figuran como espejos distorsionados de nosotros mismos nos obligan a cuestionarnos a realizar nuevas interpretaciones y a crear nuevas formas de entendernos y comunicarnos. Trabajan, en lo emocional, en lo intelectual desnaturalizando y desanquilozando formas que continuamos repitiendo porque están naturalizadas y simplemente las seguimos para poder pertenecer, para no ser un paria, para estar en el nomos. Los cambios sociales y culturales que se están produciendo últimamente nos llevan a re pensar el camino del héroe, la estructura que marca nuestros trayectos de pasaje, pero no sólo porque lo podemos pensar en femenino también, sino porque este concepto de lo masculino y femenino también es una construcción elaborada social y colectivamente durante milenios que por momentos en la actualidad parece que se "deconstruye" pero no es muy cierto hacia dónde se re- inventará. Ahí están las historias, los mitos que nos permitirán re-pensar y re-crear qué somos como humanes, tal vez con "e" y en minúscula.

\section{Bibliografía}

Berger, P. (1969) El dosel sagrado. Elementos para una sociología de la religión. Buenos Aires. Amorrortu.

Campbell, J. (1959) El héroe de las mil caras. México. FCE.

(1991) El poder del mito. Barcelona. Emece.

(2000) Los mitos en el tiempo. Buenos Aires. Emece.

Dalarum, J. (2000) La mujer a los ojos de los clérigos en Duby, G. y Perrot, M. (comp.) Historia de las Mujeres. Tomo 2. Madrid. Taurus.

Eliade, M. (1992) Mito y realidad. Barcelona. Labor.

Malosetti Costa, L. (2000) Mujeres en la frontera en Pita, Gil Lozano (comp) Historia de las Mujeres en Argentina. Madrid. Taurus.

Giunta, A. (2014) Mujeres entre activismos. Una aproximación comparativa al feminismo artístico en Argentina y Colombia en Caiana Na 4. Revista de Historia del Arte y Cultura Visual del Centro Argentino de Investigadores de Arte recuperada en http://caiana.caia. org.ar/template/caiana.php?pag=articles/article_2.php\&obj=149\&vol=4 (17/02/2020) 
Kratje, J. (2017) El cine como transgresión. Deseo, política y feminismo en Camila (María Luisa Bemberg, 1984) en La Trama de la Comunicación, Volumen 21 Número 1, enero a junio de 2017, p. 29 a 43.

Mulvey, L. (2007) El placer visual y el cine narrativo en Cordero Reiman, K. y Sáenz, I. (comp.) Crítica feminista en la teoría e historia del arte. México: Universidad Iberoamericana.

Rivera Garretas, M.M. (s/f) Parentesco y espiritualidad femenina en Europa. Una aportación a la historia de la subjetividad. Universitat de Barceleona recuperado en https://core. ac.uk/download/pdf/71014112.pdf (18/02/2020).

Trebisacce, C. (2013) Historias feministas desde la lente de María Luisa Bemberg en Revista Nomadías, Noviembre 2013, Número 18, p. 19-41

\section{Filmografía}

Bemberg, M. L. (1972) El mundo de la mujer. Cortometraje. . (1981) Momentos. Con Miguel Ángel Solá y Graciela Dufau.

. (1982) Señora de Nadie. Con Luisina Brando, Rodolfo Rani y Julio Chávez.

. (1984) Camila. Con Susú Pecoraro, Imanol Arias.

. (1986) Miss Mary. Con Julie Christie, Nacha Guevara, Tato Pavlovsky. . (1990) Yo. La peor de todas. Con Asumpta Serna, Graciela Dufau, Héctor

Alterio. (1993) De eso no se habla. Con Marcello Mastroiani, Luisina Brando.

\section{¿Women and Cinema, is there a place for heroine?}

Abstract: When Campbell talks about the hero's path, he does it in masculine. It is naturalized that this place is occupied by a hero and not a heroine. The "path" means a structure, a series of "moments" that are repeated for every hero. We see this structure repeated over and over again in most of the stories that are told to us from the very beginning of humankind to the present. What's interesting about Campbell's approach is that this structure is repeated at the level of the unconscious when we make the passage between childhood and our adult life. This is why all those stories, myths, that are told from one generation to another, are so deep in the consciousness of the humans that share the same culture. It's a path full of effort and sometimes pain to seek identity, and become an adult who is usefull to society.

In this paper we will investigate the work of an Argentine filmmaker of the twentieth century, María Luisa Bemberg, who through her work and her practice as a screenwriter and film director called into question some naturalized cultural values regarding what it is to be a woman. She did it in the subject of his films but also in her professional prac- 
tice. She is known as the first Argentine film director. She managed to be recognized for her work in an environment with a high percentage of male workers and in most of her projects she relied on the production of another woman: Lita Stantic, a place that wasn't either occupied by women. We are also going to work on some of the female stereotypes that are discussed in her filmography, historizing and contextualizing their construction.

Keywords: Cinema - Bemberg Woman - feminism - hero - heroine - myth - nomos hegemony - stereotypes.

\section{¿Mulher e Cinema, existe um lugar para heroína?}

Resumo: Quando Campbell fala sobre o caminho do herói, ele o faz no masculino. É natural que esse topos seja ocupado por um herói e não uma heroína. $\mathrm{O}$ "trajeto" encontra uma estrutura, uma série de "momentos" que se repetem no caminho de todo herói. Vemos essa estrutura repetida várias vezes na maioria das histórias que nos são contadas desde o início da humanidade até os dias atuais. O interessante da proposta de Campbell é que essa estrutura se repita no nível do inconsciente quando fazemos a passagem entre a infância e a vida adulta. É por isso que todas essas histórias, mitos, que são repetidos de geração em geração, penetram tão profundamente em todos os humanos que compartilham a mesma cultura. Todos nós passamos por esforços e, muitas vezes, com dor, na fase em que buscamos nossa identidade, na qual nos transformamos em um adulto que vai ocupar um lugar na sociedade.

Neste trabalho, investigaremos o trabalho de uma cineasta argentina do século XX, María Luisa Bemberg, que através de seu trabalho e prática como roteirista e diretora de cinema questionou alguns valores culturais naturalizados sobre o que é ser mulher. Ele fez isso no assunto de seus filmes, mas também em sua prática profissional. Ela é conhecida como a primeira diretora de cinema argentina. Ela conseguiu ser reconhecida por seu trabalho em um ambiente com uma alta porcentagem de trabalhadores do sexo masculino e, na maioria de seus projetos, apoiou-se na produção de outra mulher: Lita Stantic, um lugar que não era comum para uma mulher ocupar. Para isso, trabalharemos em alguns dos estereótipos femininos discutidos em sua filmografia, historizando sua construção.

Palavras chave: Cinema - mulher de Bemberg - feminismo - herói - heroína - mito nomos - hegemonia - estereótipos.

[Las traducciones de los abstracts fueron supervisadas por el autor de cada artículo] 